guês e Inglês, publicados até 15 de março de 2021, referentes à espécie humana, para responder à seguinte questão PICO: 'As amostras salivares são tão eficazes quanto as zaragatoas nasofaríngeas para a deteção de SARS-CoV-2 em pacientes?'. Foram incluídos artigos com estudos in vivo, nos quais é analisada a viabilidade da deteção de SARS-CoV-2 através de saliva, em comparação com amostras nasofaríngeas, tendo estas como controlo. Foram também considerados estudos com amostras salivares misturadas com secreções faríngeas e muco do trato respiratório inferior (expetoração e saliva profunda). Foram excluídos estudos com amostras constituídas apenas por pacientes infetados por SARS-CoV-2, estudos com múltiplas testagens, bem como estudos nos quais o controlo não é a zaragatoa nasofaríngea. A seleção dos artigos, extração de dados e a avaliação do risco de viés foram realizados por dois revisores. Uma síntese narrativa dos estudos foi realizada sem a junção dos dados quantitativos devido à variabilidade da metodologia encontrada. Resultados: Partindo de 434 artigos identificados, 14 estudos que cumpriram os critérios de elegibilidade foram incluídos nesta revisão sistemática, dos quais 9 casos-controlo e 5 revisões sistemáticas/meta-análises. Todos os artigos compararam a saliva com o esfregaço nasofaríngeo. Independentemente dos testes realizados, foram encontrados valores de sensibilidade entre os $51,9 \%$ e $100 \%$, e especificidades de $89,2 \%$ a $99,47 \%$ para a saliva. Conclusões: As amostras salivares podem ser utilizadas no diagnóstico de COVID-19. São especialmente úteis para testagens recorrentes e em massa. No entanto, existem algumas reservas em relação ao seu uso em pacientes em meio hospitalar, pacientes assintomáticos ou com baixa carga viral.

http://doi.org/10.24873/j.rpemd.2022.01.946

\section{\#088 O impacto do SARS-CoV-2 na ansiedade em estudantes de Medicina Dentária}

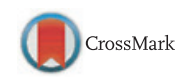

Catarina da Silva Carneiro de Braz José*, Álvaro Azevedo, Maria de Lurdes Pereira

Faculdade de Medicina Dentária da Universidade do Porto, EPIUnit - Instituto de Saúde Pública, Universidade do Porto, Laboratório para a Investigação Integrativa e Translacional em Saúde Populacional (ITR)

Objetivos: Com o surgimento da doença COVID-19 foi imposta uma nova realidade e aliada à mesma houve a modificação dos métodos de aprendizagem no curso de Medicina Dentária. Os estudantes, deparados com tais condicionantes, enfrentaram novos desafios e obstáculos, despoletando nos mesmos, estados emocionais depreciativos como a ansiedade. Esta emoção é caracterizada por sentimentos de tensão, pensamentos inquietantes e alterações físicas, sendo um estado emocional que deve ser tido em conta, primordialmente no cenário pandémico atual, de modo a minimizar o sofrimento psicológico inerente ao que o mundo tem vindo a vivenciar. Esta investigação teve como objetivo avaliar a possibilidade de a pandemia causar nos estudantes de Medicina Dentária a ansiedade. Materiais e métodos: Este estudo transversal realizado entre outubro de 2020 e maio de 2021, foi constituído por um total de 1115 participantes de um universo de aproxi- madamente 3000 alunos das 7 instituições Universitárias que lecionam o Mestrado Integrado em Medicina Dentária em Portugal, obtendo-se uma taxa de resposta de aproximadamente $37 \%$. Como ferramenta do estudo, foi aplicado um questionário de autorrelato, via online, através da plataforma Google For$\mathrm{ms}^{\circledR}$, tendo sido o mesmo dividido em 3 secções relativas à caraterização sociodemográfica dos estudantes, aos aspetos pedagógicos e, adicionalmente, uma terceira secção que incluiu questões para avaliar a ansiedade através da utilização da Escala da Ansiedade, Depressão e Stress-21 (EADS-21). Resultados: Valores categorizados como normais, dos níveis de ansiedade, foram encontrados em $41,0 \%$ dos participantes. Neste estudo, os preditores mais significativos e fortes da ansiedade destacaram-se nos estudantes do sexo feminino, na pandemia ter afetado os seus rendimentos a nível financeiro e no facto de os estudantes terem-se sentido prejudicados a nível pedagógico. Conclusões: Durante o estado pandémico, foi possível concluir que os participantes apresentaram valores elevados relativos aos níveis de ansiedade, sendo relevante referenciar a importância da adaptação futura do ensino em Medicina Dentária para colmatar as adversidades enfrentadas durante a pandemia e, consequentemente, melhorar a saúde psicológica dos estudantes.

http://doi.org/10.24873/j.rpemd.2022.01.947

\#089 Prevalência de hipodontia numa população portuguesa

Gunel Kizi*, Sara Rua, Valter Alves, Iman Bugaighis, Ana Delgado

Instituto Universitário Egas Moniz

Objetivos: A Agenesia Dentária é uma das anomalias de desenvolvimento mais frequente, na qual insere-se a hipodontia, sendo esta definida como uma ausência congénita de um a cinco dentes. O objectivo do presente estudo foi a avaliação da prevalência, padrão e distribuição de género da hipodontia, em pacientes ortodônticos portugueses. Materiais e métodos: É um estudo transversal, retrospectivo, baseado nos registos de 409 pacientes que, compareceram na consulta assistencial de ortodontia na Clinica Universitária Egas Moniz entre 2012 e 2021. Destes 409, 249 pacientes pertencem ao género feminino (61\%) e 160 ao género masculino (39\%). Foi realizada uma análise estatística descritiva de forma a determinar a frequência de hipodontia e o Chi- Square Test relacionando a frequência de hipodontia com vários parâmetros, incluindo o género e tipo de dente. Resultados: Dos 409 pacientes, 53 apresentaram agenesia dentária (12.5\% da amostra total; $29.4 \%$ género masculino e $70.6 \%$ género feminino; idade média $14.9, \mathrm{D} \pm 3.9$ anos). A prevalência de hipodontia foi significativamente superior no género feminino (9.2\%), comparativamente ao masculino (4.2\%) com $\mathrm{P}<0.05$. Foram registadas 95 agenésias na amostra total; 54 na maxila (56.8\%) e 41 na mandíbula (43.2\%). Os dentes mais frequentemente afetados, por ordem decrescente, foram: segundo pré-molar inferior (40), incisivo lateral superior (35), segundo pré-molar superior (16), canino superior (2), incisivo lateral inferior (1) e primeiro pré-molar superior (1). Conclusões: Registou-se uma prevalência de hipodontia 